\title{
The Conceptual Analysis of the Construct Multicultural Art Education
}

\section{Bill Davidson}

As the twenty-first century nears, multiculturalism is proving to be one of the most challenging and dominant topics in art education. As state educational systems scramble to develop and implement multicultural art education curricula to meet the needs of a rapidly diversifying population, the need for analytical research directed at identifying and clarifying the unifying themes of multiculturalism are of major significance for turning theory into practice (Banks 1992).

Peter Smith writing in the June 1993 issue of NAEA News stated that multiculturalism is, "...an area whose very identity, including foundational theory and implementation, is still in that infantile state" (p. 21).

In recognition that there exists a need for research directed at establishing identity to what Peter Smith calls the "foundational theory" of multiculturalism in art education, the aim of this study is to identify and clarify the unifying themes which bind multicultural art education together as a cohesive construct. The overarching question guiding this inquiry is: "What are the identifying factors of the construct multicultural art education?

The construct multicultural art education is conceived of as a complex body of unified definitions, theories, concepts, and approaches represented in multicultural art education literature. These various definitions, theories, concepts, and approaches are seen as idiosyncratic points of view from various individuals and groups. While representing different points of view these definitions, theories, concepts, and approaches are connected by unifying factors which identify them as belonging to the construct multicultural art education. Unifying factors within the construct multicultural art education are termed necessary and sufficient features (Soltis 1968).

Necessary and sufficient features provide identity, relationships, and the foundation for the construct multicultural art education. In addition, necessary and sufficient features can be consigned to what Peter Smith referred to as the "foundational theory."

In order to identify, clarify, and unify the construct multicultural art education the research method of conceptual analysis is used (Soltis 1968; Jaeger 1988). Conceptual analysis can be used to achieve the aims of establishing identity, clarity, and unity; increasing the knowledge base of the foundational theory; making distinctions between definitions and usage of terms; identifying the necessary and sufficient features; countering the

Marilyn Zurmuehlen's Working Papers in Art Education 1993 
negative effect of categorizing; and dispelling the use of labeling separatism as a category of multiculturalism.

The identification of necessary and sufficient features as they are represented in selected education literature will emerge from the analyzed and synthesized writings of four general educators, James Banks, Richard Pratte, and Christine Sleeter and Carl Grant. As criteria for analyzing multicultural art education literature the necessary and sufficient features that emerge will be compared and contrasted to the writings of six art educators. Art education jiterature will be represented by Craeme Chalmers, Kristine Congdon, Jessie Lovanno-Kerr, Mary Stokrocki, Patricia Stuhr, and Enid Zimmerman.

By meeting the above mentioned aims this study will provide future researchers and practitioners with a richer contextual meaning and understanding concerning the construct multicultural art education, a construct that emphasizes the unifying aspects of multicultural art education and not the divisions.

Unifying themes have not been adequately emphasized in art education research. Instead, in recent years the emphasis has been on making known the differences found in the literature that describes the various approaches for teaching particular needs in multicultural art education. The method of categorizing is most often found in examples of this type of research. Some of these examples are illustrated by the work of Smith (1983), Collins and Sandell (1988), Stuhr (1991), Chalmers (1992), and Tomhave (1992). The emerging result from this research method of categorizing has led to assertions that multicultural art education is fragmented and particularized (Smith 1992). In order to counter this trend of creating division which now exists in the research literature of art education it is purposed that the literature pertaining to multicultural art education be viewed as a construct based on thematic unity and not based on divisions established by categorizing teaching strategies and approaches. It is additionally purposed that this construct, here forth to be called "the construct multicultural art education," requires emphasizing of its foundational theoretical features which can assist in providing identification, unification, and clarity in the literature of multicultural art education.

\section{References}

Banks, J. A. (1992). Multicultural education: For freedom's sake. Educational Leader, 5 (2), 32-36.

Chalmers, F. G. (1992). D.B.A.E. as multicultural education. Art Education, 45 (3), 16-24.

Collins, G. and Sandell, R. (1992). The politics of multicultural art education. Art Education, 45 (6), 8-13. 
Jaeger, R. M. (1988). Complementary methods for research in education. Washington D.C.: American Educational Research Association.

Soltis, J.F. (1968). An introduction to the analysis of educational concepts. London: Addison-Wesley Pub. Co.

Smith, R. A. (1983). Forms of multi-cultural education in the arts. Journal of Multicultural and Cross-Cultural Research in Art Education, 1 (1), 23-32.

Smith, R. A. (1992). Problems for a philosophy of art education. Studies in Art Education, 33 (4), 253-266.

Stuhr, P. L. (1991). Contemporary approaches to multicultural art education in the United States. INSEA News, 1 (91), 14-15.

Tomhave, R. D. (1992). Value bases underlying conceptions of multicultural education: An analysis of selected literature in art education. Studies in Art Education, 34 (1), 48-60. 